\title{
Coordinating Investigator
}

National Cancer Institute

\section{Source}

National Cancer Institute. Coordinating Investigator. NCI Thesaurus. Code C51818.

A research scientist whose task is to see that work, or events, goes harmoniously. 